\title{
The Social Media Based-Marketing for Universities on Foreign Students' Emotions in China
}

\author{
Ali B. Abduljabar ${ }^{(1)}$,Mingfei Du ${ }^{(2)}$,Jing Zhang \\ Department: School of management "Huazhong University of science and technology", Wuhan, China, 430074
}

\begin{abstract}
Nowadays WeChat app considered as the major communication method in china .Several research marketers consider it as a key program for followers' engagement. The impact of social media and Internet networks technology on individuals behavior and decision making related to students hunting studying abroad become accustomed to the new trends and developments being more approachable and effective in adopting, implementing recruitment and marketing techniques tools for higher educational institutions. The aim of this study is to Investigate whether the social media based-marketing for universities via wechat has a direct effect on both the university brand identification linked to the foreign registered students' emotions as well as its correlation with the universities marketing methods efficiency. 200 subjects have been chosen for this study and a questionnaire has been done on them in terms of social media, brand attachment and customer engaged factors as an engagement circle, AMOS software was used for statistical analysis. The majority of subjects prefer using wechat with a (188) respondents for (94\%) followed by others social media unnamed depends to the respondents for (6) respondents and (3\%) ,meanwhile there were (5) for (2.5\%) respondents using $Q Q$ ending with one responding for using weibo for $(0.5 \%)$.Most of respondents enthusiastic about daily using and checking for their social media with (49.5\%) at scale of (agree), the majority at (46.5\%) agree and interesting about the updating news for Chinese universities in CSM.(41\%) of respondents agree that the CSM interesting rather than former usage in their countries. Wechat variable marketing questions measurement that the majority agree with keep using CSM after graduating at(44\%) with (88) respondents, additionally the majority agree at(49.5\%) that the information about Chinese university in wechat ads are useful for them, followed with (37\%) agree that they are learning from the official accounts for Chinese universities in Wechat sites. The most portion numbers of respondents foreign students agree at (36\%) that the multimedia ads of CSM represent their requirements about Chinese university with (32\%) neutral, Respondents agree emotionally connected to CSM of their university, followed at (40\%) agree that will feel emotionally attached if the recruitment reply on their feedback through the social media of their universities,ended with majority of respondents agree following others universities official accounts at (34.5\%).It has been concluded that there is a strong relation between the social media marketing and the foreign students emotions enhancing the efficiency of the Chinese universities as a brand attachment.
\end{abstract}

- The social media:

\section{Introduction}

it's a way of communication between people and associations to share information and subjects interests as news, business, ideas, technologies, photos and videos to reach the final benefits such as (a money profit, keep in touch and updating news with friends and family or advertising for products and services) inside the web 2.0 internet, mobile networks or another public or privet networks in a groups or individual.

\section{- social media based-marketing}

To classify this dimension we need first to classify it separately, the social media and marketing, respectively to reach the classification role of this dimension while we categorize the social media up ,therefore it needs to describe the marketing which is sharing the information about the services and products of the companies and organizations in set of processes describing by using a simply direct or twisted language to the end user (consumer) about what they have and consumer needs such as prices, offers, new products, new technologies and make the organization expended to the more and more users and markets.

Then the social media based-marketing mean or catalog under using the marketing up in social media to branding or customize them products or services for the end user. 
The social media based-marketing for Universities on foreign students' emotions in china

\section{- Students emotions}

The emotion can be seen in every part of our life from attitude, action, reaction or behavior related to our gender, culture, environment, our historical medical history background, the available way of expressions and others. Besides that selling, giving, marketing or advertisement of any service must know the conceptual acceptance required reaching or gain the final require benefits, Emotion research is frequently classified into psychological and sociological approaches. In order to get the nearest definition of the emotion in social media based-marketing needed to present the categorization of emotions in different science fields because the authors or researchers define the emotions under the requirements needed or their fields of interest to obtain an extensive classification to the student emotions.

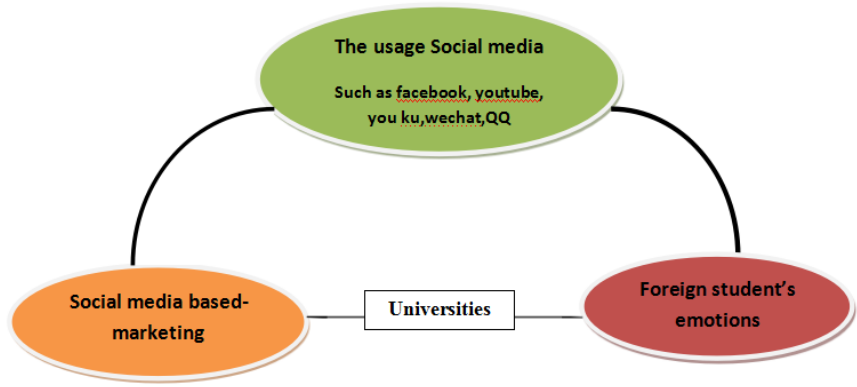

Figure 1 dimensions

- General benefits of using social media based-marketing for universities

1) Examine the implementation and the efficiency in the fields that organization interest in by increasing or decreasing the number of users inside the usage social media.

2) Define the strategy of the university for the students regarding their requirements.

3) Make the students updating in advance about the new or the developments rules for their studies.

4) Make the university in a close attach with the students by categorizing and knowing their emotions and responding comments, beside keep in touch with the alumni also after graduations for future studies and partnerships works interests.

5) Being in a close with the competitors by knowing the other universities usage social media or officials internet web and their new researchers and interesting new topics and developments methods.

6) Make the universities in globalization and internationalization to attract more talent and alumni from all over the world depending at the using language and the university interesting.

7) Discovering the loyalty of the students and universities recruitments scales.

8) Built a strength relationship between the users (students) and the recruitments (the teachers and the employees).

9) Attract more talent and researchers through the advertising of new conferences and seminars' inside the usage social media or the web 2.0.

10) Can spot specific users through the location services usage in the social media such as google, wechat.

11) The most powerful role in the social media can be seen in the availability access for all the consumers all over the world.

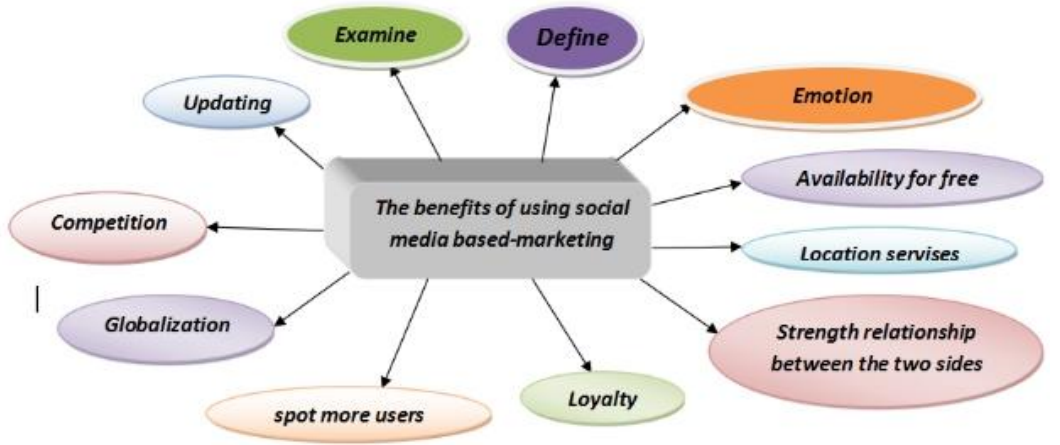

Figure 2 General benefits of using social media based-marketing for universities 
The social media based-marketing for Universities on foreign students' emotions in china

- WeChat

WeChat is an app considered the giant communication platform in china and for many abroad of china it is equaled to WhatsApp, facebook, amazon or instagram of China. Is a mobile phone voice and text messaging communication service that supports video and text chat, video/photo and location sharing, video calling, broadcasting messages, discovering new people, photo sharing and group messaging, Many marketers consider WeChat as a unique tool to engage the fans and customers of their brands. since launched to markets in Jan 2011 by tencent company in name of (weixin) means(micro message) labeled after as his name now for international markets.

For any business looking to market in china and internationally, WeChat should be at the very center of its social media based-marketing plan. Despite launching a specified six years ago, WeChat already boasts more than

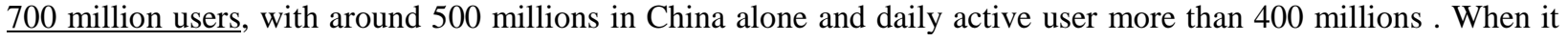
comes to social networking in China, WeChat is the unchallenged champ.

WeChat compiles many of the features and tools of the world's largest social media platforms in a simple package while incorporating every aspect of day-to-day life within it, By sound into this heavy resource, companies can roll out marketing campaigns that utilize numerous facets of the user's world.

\section{Methodology}

This study is a quantitative research formulation instrument in three sections, demographic questions, model elements understanding as a multiple choice in 5 scale to check the hypotheses of research and open-ended questions.

Table 1 questions types

\begin{tabular}{|c|c|c|}
\hline $\begin{array}{l}\text { Question types of } \\
\text { research survey }\end{array}$ & Description & $\begin{array}{l}\text { Question } \\
\text { numbers } \\
\end{array}$ \\
\hline Demographic & $\begin{array}{l}\text { For first part and its an integral part of any questionnaire, They are used to identify } \\
\text { characteristics such as age, gender, race, geographic place of residence, etc. } \\
\text { Demographic data helps to establish a more accurate picture of the group of persons } \\
\text { you are trying to understand. }\end{array}$ & Q1-Q8 \\
\hline Multiple Choice & $\begin{array}{l}\text { Consists of three or more exhaustive, mutually exclusive categories. Multiple choice } \\
\text { questions can be asked for respondents to select anywhere from or more answers. This } \\
\text { type of question may include an "other" category. }\end{array}$ & Q9(1-24) \\
\hline Open-Ended & $\begin{array}{l}\text { questions seek to explore the qualitative, in-depth aspect of a particular topic or issue. } \\
\text { It gives the respondent an opportunity to respond in more detail and to validate the } \\
\text { relevant responses. }\end{array}$ & Q10-Q15 \\
\hline
\end{tabular}

\subsection{How the questions have been designed?}

As mentioned above the questionnaire built in three sections or parts and approached to the respective foreign students respondents through the online Chinese survey website called (www.sojump.com) and send the questionnaire by wechat contacts and emails, in this website can check the respondents figures in advance to reach the minimum of needs reach to stop the survey and obtain the data from website immediately, below the description how structured the questionnaire:

\section{- Demographic section}

Built in the first part of questionnaire to check the identification of the respondents in eight questions as multiple choices design, thus demographic question sequences was for nationality according to the world continent, Age in three categories, Gender, Social status, Financial status for study and living expenses, Family members, education level(Although there was a diversity in the courses studied from the universities in china to obtain a specific degrees, we divided it to the main degrees bachelor, master and $\mathrm{PhD}$ ), the social media preferring to contact with teachers and students in china(its structured regarding to the most common usage social media apps in china now).

\section{- Multiple choice}

This part structured in 24 questions within Q9 related to the research model to check its elements through three questions each conducted to the conceptual hypothesis of this study, beside it was instrument and transformed from the related researcher basic questions in same elements to fit in the research title. Below illustrate the questions related to elements sequences as the questions in questionnaire.

\section{- Information}

The first three question (9/1-3) refer this variable to measure its quality and representing identity to improving the informativeness that provided by wechat.

\section{- Interesting}

The Qs (9/4-6) refer to this variable to measure the enthusiastic of users in social media and their interesting in two sides about the updating and checking the news to modify this variable. 
The social media based-marketing for Universities on foreign students' emotions in china

\section{- Effectiveness}

This variable refer for it by Qs(9/7-9) to improve the wechat efficiency in both long and short term as using the future intention in using it which its basic to the universities marketing technique tools beside the usefulness for the user in present time as on the side of learning which actually its basic framework of universities.

\section{- Multi methods of screening the information}

The Qs(9/10-12) refer for this variable to check its representing their requirements and to see if the comments can be also use as a methods to show the information about universities beside the ordinary methods (photos, videos, articles and voice), beside it can be shown in different colors or ways to the readers or followers regarding to the likes or written notes from the recruitments or effective followers in wechat, in brief to using it as a measurement method.

\section{- Brand attachment}

The three questions (9/13-15) instrument and structured based to the definition of(Christine Oneto, 2014), to see the impact of emotion in attaching or connecting the user to their universities and the university as brand attachment affect on the student through the competition of others universities and the university must do extra work on their official accounts in social media.

\section{- WOM Behavior}

The Qs (9/16-18) built to present this factor and measure it by knowing the efficiency of user and the impact of comments in social media sites on decisions as a significant marketing tool to check the behavior of respondents in this side.

\section{- Loyalty}

This factor measure in $\mathrm{Q}(9 / 19-21)$ by seek the impact of student loyal and trust in university decision making in present time, to continue her or his study for further studies to check the loyalty in long term after graduation and asking the respondents a direct question in their loyalty to their universities to check the factor its self.

\section{- Satisfaction}

In last for consumer satisfaction was measure by three steps, first, the satisfaction of student in the university official site, second, in the happiness with it and third with pleasing with it to see the impact of this factor.

\section{- Open-Ended questions}

This part structured to further studies and checking the marketing implementation limitations of research beside its gives the respondents more space to show their feeling, difficulties and their suggestions which helps in more ideas for more studies.

\section{- Samples of respondents}

the respondents of this study only the foreigner students who study in Huazhong university of science and technology, Wuhan, China, approached online to more than 230 two hundred thirty students from more than 2500 students study in this university with percentage near to $10 \%$ of them.

\section{- Collection of the data}

After approaching the questionnaire online for ten days to perspective student randomly, obtain the results from the website and stop the survey ended with a statistic analysis by AMOS statistic software.

\section{Results}

Regression analysis was used to investigate the hypothesis that brand attachment mediates the effect of wechat variable marketing on customer implicated factors. Wechat variable marketing Information (MeanWInfo) has a direct impact on brand attachment (BAMean) because less than 0.000 which is significant regarding to ( $\beta$ $0.000<0.05$ ) shown in table 2 below. Wechat variable marketing Interesting (MeanWInt) has a direct impact on brand attachment (BAMean) because less than 0.000 which is significant regarding to $(\beta 0.000<0.05)$ shown in table 2 below. Wechat variable marketing Effectiveness (MeanWEff) has a direct impact on brand attachment (BAMean) because less than 0.000 which is significant regarding to $(\beta 0.000<0.05)$ shown in table 2 below.

Wechat variable marketing Multi methods screening the information (MeanWMMSI) has a direct impact on brand attachment (BAMean) because less than 0.000 which is significant regarding to $(\beta 0.000<0.05)$ shown in table 2 below. Brand attachment (BAMean) has a direct impact on Consumer implicated factor word of mouth (behavior) (WOMMean) because less than 0.000 which is significant regarding to $(\beta 0.000<0.05)$ shown in table 2 below. Brand attachment (BAMean) has a direct impact on Consumer implicated factor loyalty (LMean) because less than 0.000 which is significant regarding to $(\beta 0.000<0.05)$ shown in table 2 below.

Brand attachment (BAMean) has a direct impact on Consumer implicated factor satisfaction (SMean) because less than 0.000 which is significant regarding to $(\beta 0.000<0.05)$ shown in table 2 below. 
The social media based-marketing for Universities on foreign students' emotions in china

Table 2 Regression Weights for Default model

\begin{tabular}{|lll|lllll|}
\hline & & & Estimate & S.E. & C.R. & P & Label \\
\hline BAMean & $<---$ & MeanWInfo & .071 & .013 & 5.361 & $* * *$ & par_1 \\
BAMean & $<---$ & MeanWInt & .191 & .013 & 14.720 & $* * *$ & par_2 \\
BAMean & $<---$ & MeanWEff & .174 & .013 & 13.471 & $* * *$ & par_3 \\
BAMean & $<--$ & MeanWMMSI & .688 & .013 & 52.385 & $* * *$ & par_4 \\
WOMMean & $<---$ & BAMean & .908 & .015 & 61.911 & $* * *$ & par_5 \\
LMean & $<---$ & BAMean & .874 & .026 & 33.719 & $* * *$ & par_6 \\
SMean & $<---$ & BAMean & .855 & .026 & 33.102 & $* * *$ & par_7 \\
\hline
\end{tabular}

Table 3 Standardized Regression Weights for Default model

\begin{tabular}{|lll|l|}
\hline & & & Estimate \\
\hline BAMean & $<---$ & MeanWInfo & .092 \\
BAMean & $<--$ & MeanWInt & .254 \\
BAMean & $<---$ & MeanWEff & .232 \\
BAMean & $<--$ & MeanWMMSI & .902 \\
WOMMean & $<---$ & BAMean & .975 \\
LMean & $<---$ & BAMean & .923 \\
SMean & $<---$ & BAMean & .920 \\
\hline
\end{tabular}

\section{Discussion}

That is a strength relationship between the social media based-marketing refer it by its variables which this research narrow it in four variables in WeChat app and the development of Chinese universities as brand attachment related to the time role responding due on the emotions of the consumer in three factors of emotions as register student, additionally the more improving their efficiency in the university social media more they will obtain students in short and long term from all over the world related to the social media with considerate the students emotions in this media, although cannot ignore making updating of teaching methods depends on the consumer emotions and historical testing facts made the increasing of foreigners students in china and made the Chinese universities in more high ranking for the universities all over the world which the social media and the internet is a huge part from it.

From the findings of this study we declared that the social media marketing has a strong impact on students attraction and the usage of the Wechat in Chinese universities is one of the major tools for marketing in our days now, accordingly all the universities should pay more attention for the sake of marketing regarding social media. In this study we figured out that the principle variables of social media that attract the students includes the direct contact between them and the supervisors or teachers, thus they feel more confident and get an easy way of communication with the instructors and can simply express their interests of study in advance.

Furthermore, this study also demonstrates that social media marketing has a direct effect on the brand attachment influencing the students to study and improve their education needs. In addition to the two factors above, Emotions are the key point that directly play a major base of students regarding universities selection.; comments and likes posted on the university wechat account have an intimate relation to the students emotions, therefore all of the universities should put into their consideration the enhancement of their account to get more students emotionally influenced to study there.

In order to summarize the previous factors, managers should pay attention to the following points:

1) Intensive development of their social media marketing tools and makes a regular upgrade of their latest events to attract the students especially for WeChat app as the paradigm app of this study.

2) Brand attachment amplification within the usage of wechat as a social media marketing method in Chinese universities as wechat is the most common application used.

3) Hardly work on the key factors that affect the students' emotions via social media marketing to increase the number of the students looking for study at their universities by making a separate section of employees concerning students' emotions not only for study but also for the atmosphere of life study and activities.

4) The mangers should highly consider the model of this study as one piece from the social media to consumer as students in their marketing plans tools if they want to attract more students and improve their efficiency in higher education competition nationally and globally. 
The social media based-marketing for Universities on foreign students' emotions in china

5) The marketing managers in Chinese universities should use the WeChat app as a major marketing tool in their marketing technique, regarding to it's highly speed development and contain all the features that they need to their marketing as the multi unlimited methods to show their information within its variables.

6) The marketing managers should use the benefit of translating to many languages in WeChat app the other social media apps not have this feature to attract more international students to study in their universities from different cultures all over the world and break the barrier between the students and higher education's organizations.

7) for the ease of money transfer in WeChat app within it benefits, the managers should concern it as benefit to them in paying the student's expenses, students can pay their tuition fees and others via we chat, beside can divide the installments to specific dates and terms regarding to their systems of finance.

8) As one of the respondents argue that the official accounts in Chinese social media poor and not present their university which give a suggestions to the managers to improve their information quality in their accounts.

\section{Conclusion}

Nowadays, Marketing has become the sword for any organization looking for success, going trough small companies, industries, restaurants, schools, universities and etc. In this study, Marketing for universities was the main core of the objective. As we all know that education is one of the most important targets for society, accordingly the education market is being highly improved to attract the subjects (students) to fulfill their requirements of learning. Proper university marketing has a direct impact on the prospective students based on the quality of learning that every student needs. There are several factors attracting the students, such as: student life, the atmosphere of study and research and subjects related to the students major of interests and etc.

Many students recently look for studying abroad in order to be exposed to different education systems, cultures and societies that influence their career positively. Thus, many universities are trying to improve their marketing systems for the means of students' attraction; Social media plays a major role throughout life in different purposes, mean while social media based marketing has been strongly used. We chat application was the tool of social media based marketing in this study because it has been the most used app in china especially for the higher education field, based on the questionnaire done.

Acknowledgment: This research is sponsored by the "National Natural Science Foundation of China under Grant 71272125 and 71672068 “.

\section{References}

[1]. Pekrun, Reinhard; Elliot, Andrew J.; Maier, Markus A.(2006), Achievement goals and discrete achievement emotions: A theoretical model and prospective test. Journal of Educational Psychology, Vol 98(3), Aug 2006, 583-597. http://dx.doi.org/10.1037/00220663.98.3.583.

[2]. Minna. Nummenmaa,Lauri. Nummenmaa. University students' emotions, interest and activities in a web-based learning environment,First published: March 2008, DOI: 10.1348/000709907X203733.

[3]. Fox, Elaine (2008) Emotion Science Cognitive and Neuroscientific Approaches to Understanding Human Emotions. Palgrave Macmillan. ISBN 978-0-230-00517-4.

[4]. Teresa Correa', Amber Willard Hinsley, Homero Gil de Zúñiga(2010), Who interacts on the Web?: The intersection of users' personality and social media use, Computers in Human Behavior 26:247-253 · March 2010 DOI: 10.1016/j.chb.2009.09.003 · Source: DBLP

[5]. Jamie L.Callahan Eric E.McCollum(2002), Conceptualizations of Emotion Research in Organizational Contexts, Advances in Developing Human Resources Vol. 4, No. 1 February 2002 4-21.

[6]. Neal M. Ashkanasy(2002)Diversity and Emotion: The New Frontiers in Organizational Behavior Research ,Journal of Management 2002 28(3) 307-338

[7]. René Algesheimer, Utpal M. Dholakia, Andreas Herrmann (2005) The Social Influence of Brand Community: Evidence from European Car Clubs. Journal of Marketing: July 2005, Vol. 69, No. 3, pp. 19-34.

[8]. Noël Albert, Dwight Merunka, Pierre Valette-Florence(2007). When consumers love their brands: Exploring the concept and its dimensions, Journal of Business Research, 2008, vol. 61, issue 10, pages 1062-1075

[9]. Gray, B. J., Kim, S. F. \& Llanes, V. A. (2003). Branding universities in Asian markets .The Journal of Product and Brand Management, vol. 12, no. 2, (108-120).

[10]. Charity P. (2011). Social Media Marketing: Measuring Its Effectiveness and Identifying the Target Market, UW-L Journal of Undergraduate Research XIV (2011)

[11]. Charles D.,Savvas P., Eleftherios A., Michael B. (2016).The role of brand attachment strength in higher education, Journal of Business Research, Volume 69, Issue 8, August 2016, Pages 3049-3057.

[12]. Suin K., Jin Y. B., Alice O.Do You Feel What I Feel? Social Aspects of Emotions in Twitter Conversations, Proceedings of the Sixth International AAAI Conference on Weblogs and Social Media 